\author{
Eddy Fan \\ Margaret S. Herridge
}

\title{
Finally, a time and place \\ for electrophysiological testing in critically ill patients?
}

Received: 7 September 2015

Accepted: 23 September 2015

Published online: 30 September 2015

(C) Springer-Verlag Berlin Heidelberg and ESICM 2015

E. Fan $(\bullet) \cdot$ M. S. Herridge

From the Interdepartmental Division of Critical Care Medicine, Toronto General Hospital, University of Toronto, 585 University Avenue, PMB, Toronto, ON 11-123, Canada

e-mail: eddy.fan@uhn.ca

Tel.: (416) 340-4800 ext. 5061

ICU-acquired weakness (ICUAW) is a common and debilitating complication of critical illness associated with an increased risk of mortality as well as persistent morbidity in survivors [1-3]. No clear consensus exists regarding the diagnostic criteria for ICUAW. Recent clinical practice guidelines have emphasized the primacy of the physical examination, using a Medical Research Council (MRC) subscore below 48 (maximum score 60 from six bilateral muscle groups) as the current reference standard that has been widely used in studies of ICUAW albeit with important limitations [4]. However, many critically ill patients are not awake and cooperative during their ICU admission, precluding the ability to complete an MRC-based diagnosis of ICUAW [5, 6]. As such, a number of clinicians and investigators have proposed the use of electrophysiological (EP) studies [i.e., electromyography (EMG) and nerve conduction studies (NCS)] to either complement or replace the need for volitional muscle testing in the diagnosis of ICUAW. However, abnormalities in EMG/NCS performed in critically ill patients are extremely common [7-9], and their diagnostic utility and prognostic significance remain uncertain [4] (Table 1).
In an article recently published in Intensive Care Medicine, Hermans and colleagues present the results of a prospective study evaluating the diagnostic properties of abnormal compound muscle action potential (CMAP), sensory nerve action potential (SNAP), and spontaneous electrical activity (SEA) derived from EMG/NCS in 730 critically ill patients, 432 of which also were tested for ICUAW using the MRC sumscore [10]. A reduced CMAP on day 8 of ICU admission had high sensitivity ( $89 \%$ ) but low specificity ( $41 \%$ ) for weakness, whereas reduced SNAP and abnormal SEA had low sensitivity (14 and $21 \%$, respectively) and high specificity (94 and $89 \%$, respectively). There was no meaningful difference in diagnostic properties of these measurements at day 15 . However, only a reduced CMAP at day 8 was significantly associated with increased mortality at 1 year (36 vs. $15 \%, p<0.001)$. This association remained significant after adjustment for ICUAW and other risk factors [odds ratio 2.46; $95 \%$ confidence interval (CI) 1.11-5.45], and a reduced CMAP at day 8 was also significantly associated with a higher 1-year mortality (hazard ratio 2.82; $95 \%$ CI 1.07-7.39). While the results of diagnostic properties of EP studies in critically ill patients are consistent with recent reports [11, 12], this is the first study to demonstrate the independent, long-term prognostic implications of an abnormal CMAP at day 8 of ICU admission.

The mechanism by which reduced CMAP confers increased mortality at 1-year remains unclear. Interestingly, the most logical explanation, that a reduced CMAP identifies patients with ICUAW which itself has been associated with poor outcomes, is not supported by these data as reduced CMAP was associated with 1-year mortality independent of weakness. However, CMAP may be measuring different aspects of the same phenomenon, and CMAP is not solely reflective of muscle injury, but is associated with nerve function as well [13]. Although a reduced CMAP may indeed provide a means to identify 
Table 1 Summary of selected studies using electrophysiological testing

\begin{tabular}{|c|c|c|}
\hline Study & Diagnostic & Notes \\
\hline $\begin{array}{l}\text { Bednarik et al. [9], } \\
\quad(N=46) \text { patients }\end{array}$ & $\begin{array}{l}\text { EP signs of neuromuscular involvement in } 56 \% \text { at } \\
30 \text { days }\end{array}$ & \\
\hline $\begin{array}{l}\text { Guarneri et al. [7], } \\
\qquad(N=92) \text { patients }\end{array}$ & $\begin{array}{l}30 \% \text { developed CIP and/or CIM by EP during } \\
\text { ICU stay; persistent in } 18 \text { patients at ICU } \\
\text { discharge }\end{array}$ & $\begin{array}{l}\text { At } 1 \text {-year follow up: } \\
\text { CIM-1 died, } 5 \text { recovered completely } \\
\text { CIP/CIM-1 died, } 1 \text { recovered, } 1 \text { remained tetraplegic } \\
\text { CIP- } 1 \text { recovered, } 2 \text { persisting ICUAW, } 1 \text { remained } \\
\text { tetraparetic }\end{array}$ \\
\hline $\begin{array}{l}\text { Hermans et al. [8], } \\
\quad(N=420) \\
\text { patients }\end{array}$ & $\begin{array}{l}\text { CIP/CIM diagnosis by EP more frequent in CIT } \\
\text { group than IIT group ( } 51 \text { vs. } 39 \%, p=0.02 \text { ) }\end{array}$ & $\begin{array}{l}\text { CIP/CIM independent risk factor for prolonged mechanical } \\
\text { ventilation (OR } 1.85,95 \% \text { CI } 1.17-2.93 \text { ) } \\
\text { Independent risk factors for abnormal EP: prolonged infusion } \\
\text { of NMBA (OR 2.01, } 95 \% \text { CI } 1.10-3.99) \text {, age (OR } 0.98 \text { per } \\
\text { year, } 95 \% \text { CI } 0.96-0.99 \text { ), and days of glucocorticoid } \\
\text { treatment (OR } 0.97 \text { per day, } 95 \% \text { CI } 0.94-0.99 \text { ) }\end{array}$ \\
\hline $\begin{array}{l}\text { Weber-Carstens } \\
\quad \text { et al. [11], } \\
\quad(N=56) \text { patients }\end{array}$ & $\begin{array}{l}61 \% \text { had abnormal dmCMAP indicating a } \\
\text { myopathic process within a week after ICU } \\
\text { admission } \\
\text { Abnormal dmCMAP predicted ICUAW upon } \\
\text { awakening with Sn } 83 \% \text { and Sp } 89 \%\end{array}$ & $\begin{array}{l}\text { Abnormal dmCMAP significantly associated with subsequent } \\
\text { diagnosis of ICUAW (OR } 0.47 \text { per } \mathrm{mV}, 95 \% \text { CI } \\
0.28-0.79 \text { ) }\end{array}$ \\
\hline $\begin{array}{l}\text { Wieske et al. [12], } \\
\qquad(N=35) \text { patients }\end{array}$ & $\begin{array}{l}\text { Ulnar SNAP }<17.6 \mu \mathrm{V}-\mathrm{Sn} 100 \%(95 \% \mathrm{CI} \\
\text { 68-100\%), Sp } 79 \%(95 \% \mathrm{CI} 49-95 \%) \\
\text { EDB peroneal CMAP <0.43 mV - Sn } 80 \% \\
\text { (95\% CI 52-96 \%), Sp } 75 \%(95 \% \text { CI } \\
\text { 48-93\%) } \\
\text { Both ulnar SNAP and EDB peroneal CMAP } \\
\text { abnormal - Sn } 77 \%(95 \% \text { CI 46-95\%), Sp } \\
100 \%(70-100 \%)\end{array}$ & $\begin{array}{l}\text { Diagnostic accuracy for ICUAW may be improved using } \\
\text { ICU-based cutoff values (rather than healthy controls) }\end{array}$ \\
\hline
\end{tabular}

$C I$ confidence interval, $C I M$ critical illness myopathy, $C I P$ critical illness polyneuropathy, $C I T$ conventional insulin therapy, $d m C M A P$ direct muscle stimulation compound muscle action potential, $E D B$ extensor digitorum brevis, $E P$ electrophysiology, $I C U$ intensive care unit, ICUAW ICU-acquired weakness, IIT intensive insulin therapy, $N M B A$ neuromuscular blocking agent, $O R$ odds ratio, $S n$ sensitivity, $S p$ specificity high-risk patients with ICUAW, the presence of this abnormality confers additional risk for poor outcomes that may represent a severe form of weakness with different pathophysiology or mediation through other pathways. Whether this represents subclinical weakness or some other form of important neuromuscular dysfunction that is causally associated with mortality requires further investigation. Alternatively, EP study abnormalities such as a reduced CMAP may be an epiphenomenon that is a marker for non-neuromuscular derangements that are causally related to increased mortality.

This study suggests a re-evaluation of the optimal timing and place for EP studies in the diagnosis of ICUAW in critically ill patients. In the recent American Thoracic Society (ATS) guidelines on the diagnosis of ICUAW, the assessment of muscle strength using the MRC sumscore was emphasized as the most commonly used and current primary modality for identifying weak patients [4]. However, given that a reduced CMAP during ICU admission may identify a subgroup of patients at high risk for both morbidity and mortality, its presence may warrant heightened surveillance and follow-up. Given the cost, resources, and relative invasiveness (as compared to physical examination), the ability to screen and diagnose ICUAW earlier with EP testing will only be useful if it is linked to an important patient-centerd outcome for which there is a robust therapeutic intervention that can modify dysfunction if applied early. Currently, there is a paucity of evidence that making a diagnosis of ICUAW, early or not, will lead to improved clinical outcomes. However, this might be a subgroup of patients who warrant early, intensive physical and occupational therapy to prevent further deterioration in neuromuscular function and perhaps lead to improved functional outcomes $[14,15]$. Although the provision of early physical and occupational therapy in the ICU appears safe, with few adverse events in previous studies, the concerning results of the AVERT (A Very Early Rehabilitation Trial) study in stroke patients give pause regarding the optimal timing and dose of rehabilitation in acutely ill patients [16]. In addition, there is emerging literature suggesting that pre-existing disability, sarcopenia, and frailty may be important factors related to the patient's inherent ability to recover physical function rather than recovery being primarily dependent on the nature of the underlying injury (Table 1) or application of rehabilitation programs [17, 18]. A clinical trial evaluating the safety and efficacy of early rehabilitation in this high-risk subgroup with a reduced CMAP should be considered. Until then, the use of EP testing in critically ill patients during the first week 
of ICU admission could be considered to help clinicians identify patients at higher risk of 1-year mortality, help inform prognostic discussion with patients and their caregivers, and focus attention on patients who may have a more difficult trajectory of recovery following critical illness.

\section{References}

1. Fan E, Dowdy DW, Colantuoni E et al (2014) Physical complications in acute lung injury survivors: a two-year longitudinal prospective study. Crit Care Med 42:849-859. doi: 10.1097/CCM.0000000000000040

2. Hermans G, Van Mechelen H, Clerckx B et al (2014) Acute outcomes and 1-year mortality of intensive care unitacquired weakness. A cohort study and propensity-matched analysis. Am J Respir Crit Care Med 190:410-420. doi:10.1164/rccm.201312-2257OC

3. Herridge MS, Tansey CM, Matte A et al (2011) Functional disability 5 years after acute respiratory distress syndrome. $\mathrm{N}$ Engl $\mathrm{J}$ Med 364:1293-1304. doi: 10.1056/NEJMoa1011802

4. Fan E, Cheek F, Cheek F et al (2014) An official American Thoracic Society clinical practice guideline: the diagnosis of intensive care unit-acquired weakness in adults. Am J Respir Crit Care Med 190:1437-1446. doi: 10.1164/rccm.201411-2011ST

5. Hough CL, Lieu BK, Caldwell ES (2011) Manual muscle strength testing of critically ill patients: feasibility and interobserver agreement. Crit Care 15:R43. doi:10.1186/cc10005

6. Vanpee G, Hermans G, Segers J, Gosselink R (2014) Assessment of limb muscle strength in critically ill patients: a systematic review. Crit Care Med 42:701-711. doi: 10.1097/CCM.0000000000000030
7. Guarneri B, Bertolini G, Latronico N (2007) Simplified electrophysiological evaluation of peripheral nerves in critically ill patients: the Italian multicentre CRIMYNE study. Crit Care 11:R11. doi:10.1186/cc5671

8. Hermans G, Wilmer A, Meersseman W et al (2007) Impact of intensive insulin therapy on neuromuscular complications and ventilator dependency in the medical intensive care unit. Am J Respir Crit Care Med 175:480-489. doi:

10.1164/rccm.200605-665OC

9. Bednarik J, Lukas Z, Vondracek P (2003) Critical illness polyneuromyopathy: the electrophysiological components of a complex entity. Intensive Care Med 29:1505-1514. doi: 10.1007/s00134-003-1858-0

10. Hermans $G$ et al (2015) Predictive value for weakness and 1-year mortality of screening electrophysiology tests in the ICU. Intensive Care Med. doi: 10.1007/s00134-015-3979-7

11. Weber-Carstens S, Koch S, Spuler S et al (2009) Nonexcitable muscle membrane predicts intensive care unitacquired paresis in mechanically ventilated, sedated patients. Crit Care Med 37:2632-2637. doi: 10.1097/CCM.0b013e3181a92f28

12. Wieske L, Verhamme C, Witteveen E et al (2015) Feasibility and diagnostic accuracy of early electrophysiological recordings for ICU-acquired weakness: an observational cohort study. Neurocrit Care 22:385-394. doi: 10.1007/s12028-014-0066-9
13. Tankisi $\mathrm{H}$, Otto $\mathrm{M}$, Pugdahl $\mathrm{K}$ et al (2012) Correlation between compound muscle action potential amplitude and duration in axonal and demyelinating polyneuropathy. Clin Neurophysiol 123:2099-2105. doi: 10.1016/j.clinph.2012.04.002

14. Burtin C, Clerckx B, Robbeets $C$ et al (2009) Early exercise in critically ill patients enhances short-term functional recovery. Crit Care Med 37:2499-2505. doi:10.1097/CCM.0b013e3181a38937

15. Schweickert WD, Pohlman MC, Pohlman AS et al (2009) Early physical and occupational therapy in mechanically ventilated, critically ill patients: a randomised controlled trial. Lancet 373:1874-1882. doi: 10.1016/S0140-6736(09)60658-9

16. AVERT Trial Collaboration group, Bernhardt J, Langhorne P et al (2015) Efficacy and safety of very early mobilisation within $24 \mathrm{~h}$ of stroke onset (AVERT): a randomised controlled trial. Lancet 386:46-55. doi: 10.1016/S0140-6736(15)60690-0

17. Batt J, dos Santos CC, Cameron JI, Herridge MS (2013) Intensive care unitacquired weakness: clinical phenotypes and molecular mechanisms. Am J Respir Crit Care Med 187:238-246. doi:10.1164/rccm.201205-0954SO

18. Iwashyna TJ, Netzer G (2012) The burdens of survivorship: an approach to thinking about long-term outcomes after critical illness. Semin Respir Crit Care Med 33:327-338. doi: $10.1055 / \mathrm{s}-0032-1321982$ 